\title{
Local positive feedback and the persistence and recovery of fringe Avicennia marina (Forssk.) vierh. mangroves
}

\author{
T. J. Huisman $\cdot$ F. Van Langevelde $\cdot$ \\ W. F. De Boer
}

Received: 6 November 2008/Accepted: 10 March 2009/Published online: 25 March 2009

(C) The Author(s) 2009. This article is published with open access at Springerlink.com

\begin{abstract}
While mangrove restoration efforts are reasonably successful, failure often occurs in high wave energy situations. Due to differences in wave energy, seedling mortality rates vary strongly with position on the intertidal flat between high water spring and high water neap elevations. However, a local positive feedback can be present between the pneumatophores of adult mangroves and the survival of mangrove seedlings to trigger recovery. In this study, a mangrove population of Avicennia marina is modelled to determine the effects of seedling mortality and local positive feedback on mangrove recovery. The model uses life history data and dispersal to simulate population dynamics. The mangrove range limits are determined by high water spring and high water neap levels. The results indicate that within these limits mangrove populations with life-history parameter values as derived from literature are indeed capable of fast growth under conditions with low seedling mortality. Local positive feedback has then a small positive influence on population recovery after mangrove loss. If, however, mortality rates increase,
\end{abstract}

T. J. Huisman · F. Van Langevelde · W. F. De Boer ( $\square)$ Resource Ecology Group, Wageningen University, Droevendaalsesteeg 3a, 6708 PB Wageningen,

The Netherlands

e-mail: fred.deboer@wur.nl such as in high wave energy situations, the importance of a positive feedback increases. The model shows that a positive feedback may, given high seedling mortality rates, be an important factor for mangrove recovery. While a positive feedback may enable mangrove persistence in unfavourable conditions, destruction of adult mangroves can remove the positive feedback, which would render the system uninhabitable and practically prohibits reforestation of such areas. The model results and the presence of positive feedbacks and their importance for population dynamics in harsh conditions indicate that investigating and understanding possible feedbacks could be crucial for successful restoration efforts.

Keywords Seedlings · Intertidal vegetation · Reforestoration · Spatial modelling

\section{Introduction}

Mangroves are subtropical and tropical forests found near estuaries and intertidal zones. They are among the most productive ecosystems in the world (Riley and Kent 1999; Saenger and Snedaker 1993), are important for coastal protection (Barbier 2006; Imbert et al. 2000), and are used as breeding grounds by a wide range of species (Imbert et al. 2000; Nagelkerken et al. 2008). Research on mangroves has focused on zonation patterns (Bunt 1996; Ellison et al. 2000; Hogarth 1999), and on relations between gradients of abiotic 
factors, such as salinity, and species occurrence (Blasco et al. 1996; Delgado et al. 2001; Hogarth 1999). Recently the decrease of mangroves (Alongi 2002; Ellison 2000) has triggered a number of studies aimed at unravelling the factors that are responsible for differences in the spatial distribution of mangroves, which could ultimately be used for restoration purposes (Bosire et al. 2008; Ellison 2000; Hogarth 1999; Imbert et al. 2000; Riley and Kent 1999; Twilley et al. 1998; Walters 2004). In restoration it is important to understand which factors determine whether or not a certain area will allow successful reforestation. Recovery efforts are generally successful in areas in which natural recruitment occurs and have failed in areas with high wave energy (Riley and Kent 1999). The failure of mangrove restoration in these situations is often caused by high seedling mortality rates (Riley and Kent 1999). Kitaya et al. (2002) measured seedling mortality on different elevations on tidal flats, and found that mortality varies strongly with elevation. Elevation correlates strongly with wave action, inundation and other related factors such as $\mathrm{pH}$ (Hogarth 1999). The mortality rates of seedlings can thus be represented using the relationship between elevation and mortality.

Recently, it has been reported that Avicennia marina (Forssk.) vierh. pneumatophores increase seedling survival by protecting seedlings against covering by algae and rubbish, and reduce wave energy (Bhat et al. 2004; Shigeyasu 2000). This protection acts as a positive feedback as more surviving seedlings lead to increasing density of adult mangroves with corresponding pneumatophores, which in turn further protect seedlings. Given the importance of seedling survival for mangrove reforestation (Bosire et al. 2008; Riley and Kent 1999) and the impact of positive feedback on different ecosystems (De Boer 2007; Rietkerk et al. 2002; Van de Koppel et al. 2001; Van Langevelde et al. 2003), it is hypothesized that the presence of a local positive feedback in mangroves may strongly influence mangrove recovery and restoration. To test this we analyse the effect of a positive feedback by modelling the dynamics of a recovering A. marina population in the presence and absence of local positive feedback and for differences in seedling mortality across the tidal flat. Dispersal and establishment of mangrove seedlings in this tidal flat are related to elevation and tidal regime.

\section{The model}

\section{Life-history of mangroves}

The model is parameterised using data on the common mangrove species A. marina. The lifehistory parameters are similar to those used by Clarke (1995). Clarke (1995), however, distinguished seven stages: propagules, cotyledonary seedlings, seedlings, saplings, young trees, trees and old trees. In this study, we simplified the life cycle into four stages; within these stages mortality and survival rates are assumed to be equal:

1) Propagules are the dispersing elements of mangroves. Propagules drop from the trees and are transported by water. The outcome of this waterbased dispersal is influenced by characteristics of the propagules. Buoyancy is regarded as an important factor as well as the period of obligate dispersal and anchoring time (Clarke and Myerscough 1991; Clarke 1993; Delgado et al. 2001). A. marina propagules have an obligatory dispersal period of around 10 days (Clarke 1993; Clarke et al. 2001; Hogarth 1999). A. marina propagules live for around 110 days; within a year propagules either develop into seedlings or perish (ElAmry 1998).

2) Propagules that have successfully established become seedlings. Seedlings are $0-10$ years old. Without light, seedlings cannot develop into saplings. This stalled development may lead to a "seedling bank" (Clarke and Allaway 1993; Minchinton and Dalby-Ball 2001).

3) Saplings are the seedlings that have continued their development. Saplings are 10-20 years old trees not yet in their reproductive phase (Clarke 1995). Mangroves may be able to reproduce around their fifth year. Usually, however, reproduction starts around their 20th year (Clarke 1995).

4) Adult mangroves have full pneumatophore cover and are capable of reproduction. Mangrove trees have been divided into three classes by Clarke (1995) since there are differences in the amount of propagules produced by young and old trees. In our model however, only one adult stage is used and each adult mangrove tree produces on average 250 propagules per year (Clarke 1995). 
We assume a stage-structured life-history, with stage-specific mortality and reproduction parameters. However, the growth of trees is dependent on the local environment, most notably the availability of space and sunshine. The seedlings and saplings at different locations are therefore not subjected to similar conditions. To model this we only counted the number of years an individual spent in the sun as its growth years. Both seedlings and saplings require ten growth years. The yearly survival probabilities for seedlings or saplings have been derived using data on transition probabilities and mortality in previously developed stage-based models (e.g. Clarke 1995).

The mangrove population's life-history as represented in the model can be summarised using a matrix model with transition probabilities on the subdiagonal and a survival probability and fertility parameter for the adult mangroves. This matrix model does not include the (spatial) effects of elevation or positive feedback. Analysis of the eigenvalues of this matrix provides information on minimal requirements for population growth as well as on the extent to which the model with elevationdependent mortality and positive feedback deviates from this simple matrix model.

\section{The tides}

Propagules disperse only when submerged or floating. The water level, however, varies with the tides. Tides are modelled using a simple sine function:

$W(t)=a \sin \left(\frac{2 \pi t}{T_{\text {tides }}}\right)$

where $W(t)$ is the water level in meters above or below average water level, $a$ the tidal amplitude and $T_{\text {tides }}$ the tidal period (days). With fixed amplitude, this equation does not model the differences between neap and spring water levels. The amplitude of the tides varies with time. The variation in time is determined by the neap-spring period. Again using a simple sine function to model the tidal amplitude, we get:

$a(t)=m+A \sin \left(\frac{2 \pi t}{T_{\text {neap }- \text { spring }}}\right)$

where $A$ is the variation of the amplitude $(\mathrm{m}), m$ the mean tidal amplitude $(\mathrm{m})$, and $\mathrm{T}_{\text {neap-spring }}$ the period of the neap-spring cycle (days). The amplitude of the tides has a certain minimal level at neap tides. This amplitude at neap tide is half the difference between high and low water. At high water the amplitude of the tides is at its maximum. Using data from De Boer (2002), we get $\min (A)=0.4$ and $\max (A)=1.4$. The mean amplitude therefore equals 0.9 and $A=0.5$. The tidal period is $12 \mathrm{~h}$ and $25 \mathrm{~min}$, which means $T_{\text {tides }}=0.52$, so that the water level in meters above or below average water level $W(t)$ can be modelled as:

$W(t)=\left(m+A \sin \left(\frac{2 \pi t}{T_{\text {neap }- \text { spring }}}\right)\right) \sin \left(\frac{2 \pi t}{T_{\text {tides }}}\right)$

with $m=0.8 \mathrm{~m}, A=0.6 \mathrm{~m}, T_{\text {neap-spring }}=18$ days, and $T_{\text {tides }}=0.52$ days.

The tidal area

The tidal area is defined in two dimensions and is represented by a matrix with $x \times y$ cells. We assume that elevation follows a simple linear slope from sea to shore along the $x$ coordinates. Mangroves occur in the tidal regions and their shore-ward limit can be adequately described by spring high-water (De Boer et al. 2000; Hogarth 1999). Hence, the system's upper boundary $\left(H_{\max }\right)$ is set $0.2 \mathrm{~m}$ above the highest spring tide and its lower boundary $\left(H_{\min }\right) 0.2 \mathrm{~m}$ lower than the lowest neap:

$H(x)=H_{\min }+s x$

where $H(x)$ is the beach height along the $x$ coordinates, which varies between $x=0$ to $x=x_{\max }$, and $s$ is the slope, defined as:

$s=\left(H_{\max }-H_{\min }\right) / x_{\max }$

Dispersal and establishment

Dispersal is modelled as stochastic movement from cell to cell. Propagules will only disperse when they are floating and the location of propagules on the tidal flat will determine at what time they will be submerged and begin to disperse. The time and the duration of dispersal are in this way dependent on the tides and the slope of the tidal flat. During flood the movement probability towards shore increases, while during ebb the movement probability towards sea increases. The result is a random dispersal influenced or skewed by the tides. 
Dispersal ends if either a propagule settles on the shore or after the A. marina propagules have reached their maximum life-span of roughly 100 days (Hogarth 1999). It is assumed that while the water level is higher than the position of the propagule on the shore, the propagule cannot develop into a seedling due to wave action and/or submergence. For a propagule to establish, it needs to form roots. The period to root initiation for A. marina propagules is 2-4 days (Clarke and Kerrigan 2002). The time to "settle firmly" or "anchoring time" $\left(T_{\text {anc }}\right)$ however is 6-10 days (Shigeyasu 2000). In the model this parameter determines the time a propagule needs to be undisturbed by tidal currents, wave stress, or algae in order to settle firmly and develop into a seedling.

\section{Local feedbacks}

There is a negative influence of the presence of mangroves on the development of seedlings and saplings in their surroundings. This negative feedback is mainly caused by shortage of light, which stalls the development of seedlings and saplings (Clarke and Allaway 1993; Minchinton and DalbyBall 2001). It is assumed that this is directly under the canopy. As the size of each cell is roughly equal to the average size of a single mangrove tree canopy, local negative feedback is limited to the cells in which an adult mangrove resides ( $\sim 5$ by $5 \mathrm{~m}$ ).

The positive feedback between pneumatophore presence and seedling survival, however, extends far beyond the canopy (Hogarth 1999). It is assumed therefore that pneumatophores are present in all 8 cells surrounding a cell in which an adult mangrove tree grows.

\section{Seedling mortality as function of elevation}

Kitaya et al. (2002) measured seedling survival for seven different mangrove species on different elevations on the tidal flat. Their findings indicated that mortality rates are both strongly dependent on elevation and are species specific. Kitaya et al. (2002) did not, however, measure seedling survival for A. marina. We therefore assume that the relation between mortality and elevation can be described using a Hill-like function:
$\operatorname{SeM}(x)=\operatorname{SeM}_{\max }-\frac{H(x)^{2}}{H(x)^{2}+h^{2}} \operatorname{SeM}_{\max }$

in which $\mathrm{SeM}_{\max }$ is the maximum seedling mortality and $h$ the half-saturation constant. It is assumed that seedling mortality is maximal at sea, i.e. seaward from the tidal flat, and equals 1 .

\section{Results}

The matrix model is subjected to a sensitivity analysis in which the growth of mangroves starting from a very low number of adult trees (10) is followed for different mortality and reproduction parameters. First, we analyse the model with a constant seedling mortality rate, and subsequently the model is extended with a mortality rate that depends on the elevation, and with a local positive feedback.

Population dynamics with constant seedling mortality and without positive feedback

Mangrove recovery is based upon successful dispersal and establishment. Varying the number of propagules produced per mangrove, or the number of propagules that survive should therefore influence the growth rate of the recovering population. Calculating the eigenvalues of the matrix model for different values of successfully established seedlings shows that the lower limit for successful recovery is 0.1 established propagules per adult mangrove.

The growth of the population is predictably influenced by propagule mortality. For all propagule mortality rates, growth is fast with populations reaching their maximum size within 100 years (Fig. 1a). The quick increases in the population size after 20 and 40 years are caused by the fixed age transitions; the mangrove number can increase only after an initial 20 years of development. The population growth rate is reduced if the propagule mortality rate is larger than 0.7 (Fig. 1a), indicating that propagule availability does not limit growth if at least $30 \%$ of the propagules become established. The value for propagule mortality reported in the literature is highly variable (Clarke 1995; ElAmry 1998; Hogarth 1999), and was taken as on average 0.95. However, even with propagule mortalities as high as 0.98 the population growth is such that after 

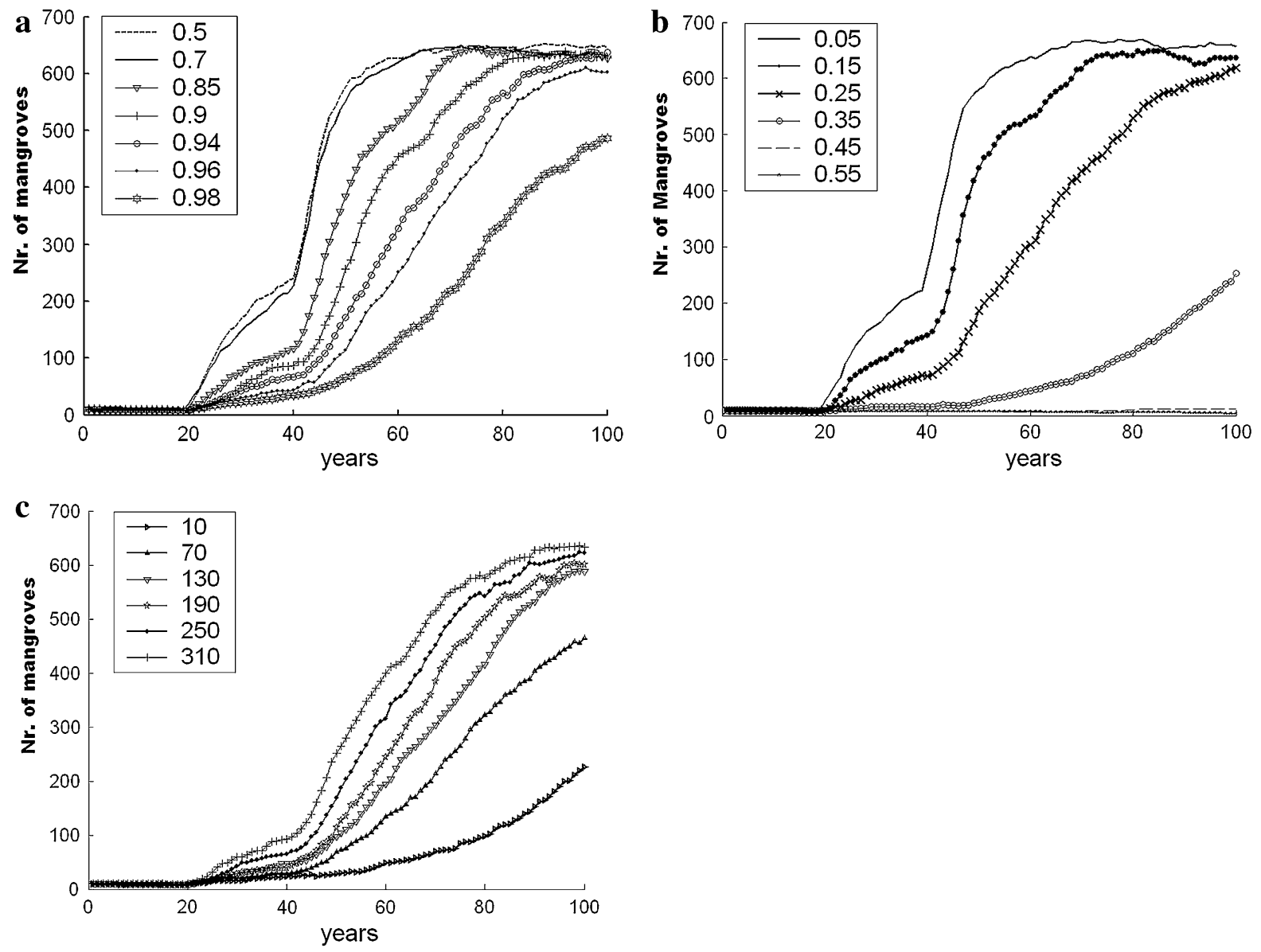

Fig. 1 Number of adult mangrove trees over time starting with 10 trees for a different propagule mortalities (ranging from 0.5 to 0.98 ), $\mathbf{b}$ different values number of propagules produced per mangrove tree (ranging from 10 to 310 ), and $\mathbf{c}$ for different

100 years the mangrove trees will have increased 40-fold, although population recovery is slower. A similar analysis for different values of propagules produced per mangrove again shows that the population recovers under all conditions, even when mangroves produce only 10 propagules (Fig. 1b).

One of the most important model parameters is seedling mortality. If it is assumed that the number of established propagules per mangrove equals 1 , the eigenvalue analysis leads to growth when the seedling mortality rate is maximally 0.38 . The seedling mortality is 0.25 and is varied here from 0.05 to 0.55 (Fig. 1c). With the mortality rate of 0.45 and 0.55 , the population does not recover, while growth is relatively slow with a mortality rate of 0.35 .

The mortality rate of saplings is lower, and their mortality is expected to have a large impact on

constant seedling mortality rates (ranging from 0.05 to 0.55 ). The model does not include elevation-dependent seedling mortality rates or the local positive feedback

population growth. Again we use the eigenvalue analysis to get a condition for growth at a sapling mortality $<0.17$. However, the mangroves successfully reproduce even when their mortality rate is 0.2 (Fig. 2). This is because we have, for the eigenvalue analysis, assumed that the number of established propagules is 1 ; this shows it is higher in the actual model.

Predictably, growth is most sensitive to changes in adult mangrove mortality. Increasing the mortality of adult mangroves decreases both the population growth and the maximum number of mangroves (Fig. 2b). The maximum population size is limited by the size of the tidal flat (i.e. the number of cells) and the lag time between the death of a mangrove tree, and the successful replacement by a seedling or sapling becoming an adult tree. In our small tidal 

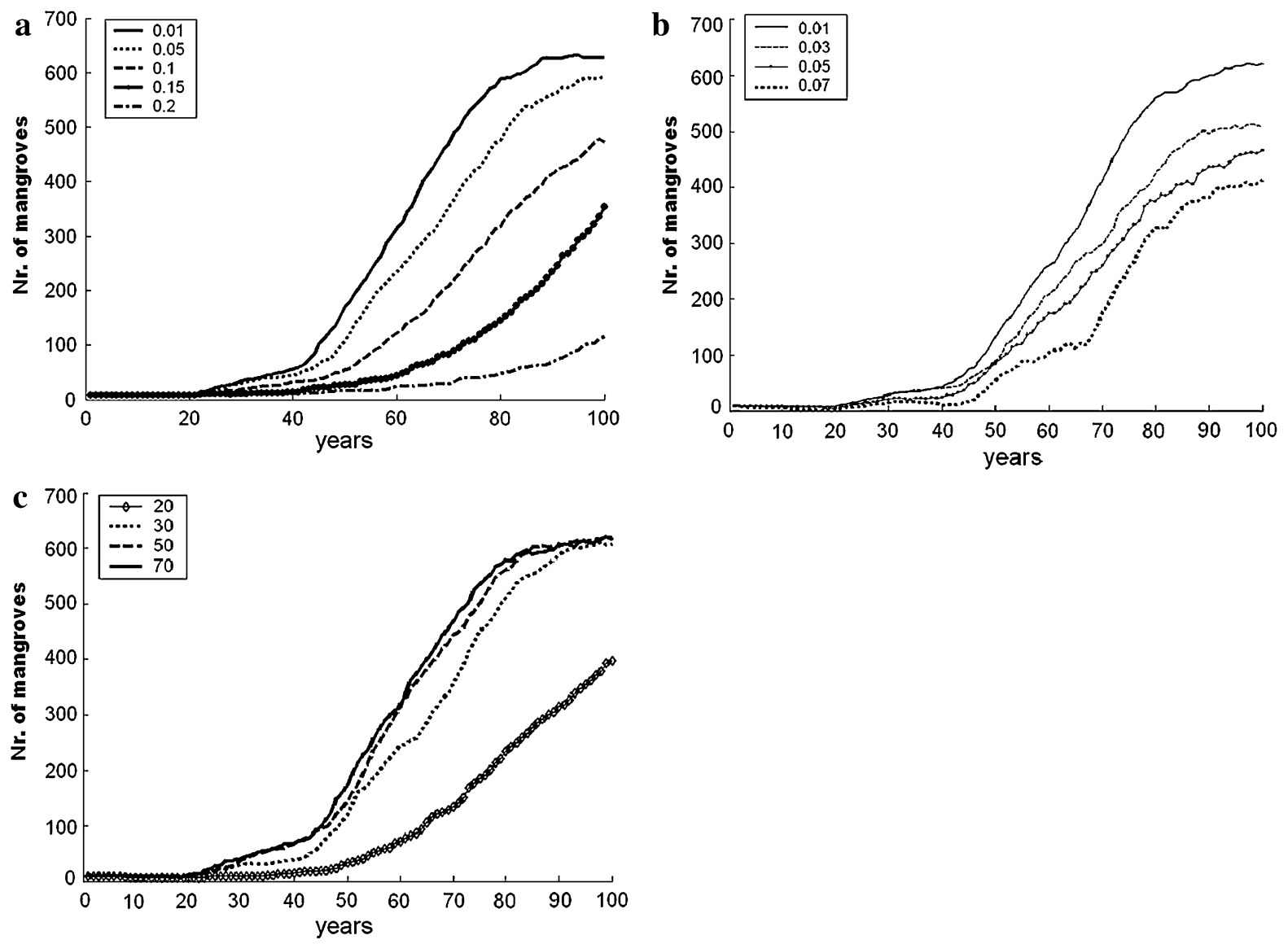

Fig. 2 Number of adult mangrove trees over time starting with 10 trees for a different sapling mortalities (ranging from 0.01 to 0.2 ), b different adult mangrove mortalities (ranging from 0.01

flat, increasing the dispersal speed does not increase population growth speed strongly (Fig. 2c). Decreasing the dispersal, however, does limit population growth which implies that in larger systems dispersal may be a factor that limits population growth.

Population size and seaward range limit

The maximum population size is determined by the seaward range limit. We can derive the relation between tidal period and seaward range limit directly from the function for tidal amplitude (Eqn. 2) and the slope of the tidal area (Eqn. 5) as:

$\min (a(t))=a\left(0.75 \cdot T_{\text {neap-spring }}\right)=m-A=0.2$

to 0.07 ), and $\mathbf{c}$ different dispersal times in days (ranging from 20 to 70). The model does not include elevation-depending seedling mortality rates or the local positive feedback

The tidal amplitude determines the duration of the undisturbed period at each level of elevation. Adding half the time required anchoring (since the total time undisturbed is half before and half after the lowest neap tide), we get the lowest elevation where establishment is possible as function of anchoring time (Fig. 3):

$$
\begin{aligned}
& a\left(0.75 T_{\text {neap-spring }}+0.5 T_{\text {anc }}\right) \\
& \quad=m+A \sin \left(\frac{2 \pi\left(0.75+0.5 T_{\text {anc }}\right)}{T_{\text {neap }- \text { spring }}}\right)
\end{aligned}
$$

The anchoring time of an A. marina propagule is 6 days; this limits the range for successful anchoring to locations that are situated $0.6 \mathrm{~m}$ above and $1.4 \mathrm{~m}$ below high water spring. In our tidal flat of $50 \times 50$ cells, there are therefore 625 available cells for 
mangroves. This is indeed approximately the maximum population size calculated (Figs. 1, 2).

Including elevation-dependent seedling mortality and local positive feedback

The introduction of elevation-dependent seedling mortality causes lower densities near the seaward fringe (Figs. 4, 5). In cases with high seedling mortality (0.5-0.6), this creates a transition from lower to higher density from sea to shore (Fig. 5a), different from the sharp seaward boundary of mangrove occurrence when seedling mortality is elevation-independent (Fig. 5b). The seaward range limit is then not determined by anchoring time (as in Eqn. 8), but mainly by seedling survival.

The positive feedback between mangroves and seedling survival leads to an increase in the recovery rate since there is a higher probability that seedlings survive and become adult mangroves trees. The effect of this positive feedback on mangrove recovery is, however, small when reproduction and survival rates found in the literature are used. The growth rate is relatively high and the presence of a positive feedback only increases the population growth slightly (Fig. 6). The effect of a positive feedback is larger if the seedling mortality rate is increased and elevation-dependent (Figs. 4, 5, 6). The mangrove

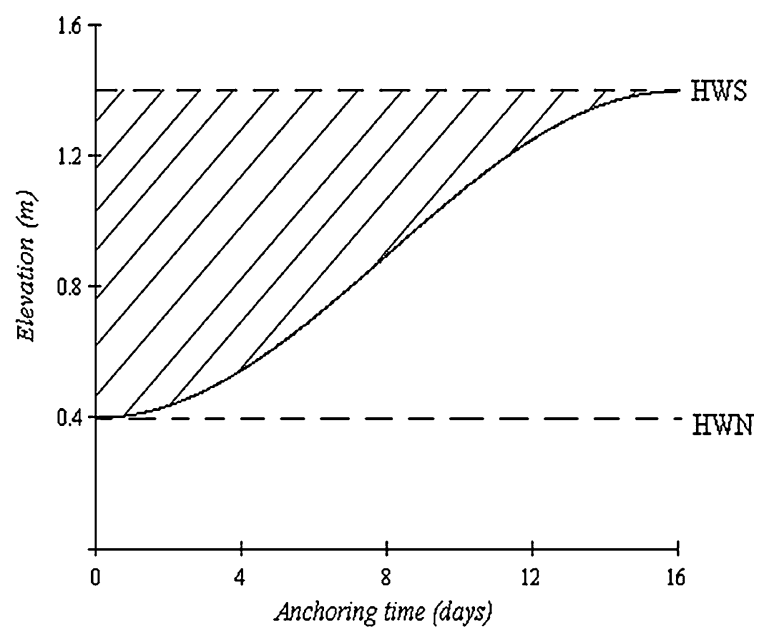

Fig. 3 The shaded area indicates where mangroves could occur given the anchoring time along the $x$ coordinates. The striped lines indicate the water level at high water neap (HWN) and high water spring. The shape of the shaded area is determined by the tidal-regime recovery as a function of mortality and average positive feedback is shown in Fig. 6. The results show that with sufficiently high seedling mortalities (above 0.45) the mangrove population can only persist if a positive feedback is present (Fig. 6). The outer seaward fringe of mangroves is the region with highest seedling mortality and is therefore even more dependent on and sensitive to the existence of a positive feedback (Figs. 4, 5).

\section{Discussion}

The results show that $A$. marina populations can, in theory, grow and recover quite fast under conditions of average mortality and survival rates as found in the literature. The high growth rates and the relative insensitivity to changes in survival and establishment of propagules and seedlings seem to indicate that mangroves' strategy of reproduction is adapted to less favourable conditions with higher losses, especially for the young growth stages. Indeed, studies have reported quite a high variability in propagule and seedling survival (Bhat et al. 2004; Clarke and Kerrigan 2002; Clarke et al. 2001; Hogarth 1999; Kitaya et al. 2002). Given the life-history parameters in our model, reforestation should present no problem in most areas. Although this indeed seems to be true for some cases, important factors not included in the model, such as biotic interactions (e.g. seed predation) and community involvement (or lack thereof) can trouble restoration even in such cases (Bosire et al. 2008; Ellison 2000; Walters 2004).

The range limit suggested by the model without elevation-dependent seedling mortality and without local positive feedback occurs at high water neap level. The range should actually be limited even to above high water neap. The high water neap level has indeed been reported as an approximate limit for the occurrence of mangroves (e.g. De Boer et al. 2000; Hogarth 1999), but mangrove species are able to occur even in those regions that are submerged every tide (Hogarth 1999). This is because some species are able to fixate to the substrate even while they are submerged. Some Rhizophora $s p$. for instance have sinking seedlings (Hogarth 1999). So although approximately true for species with non-sinking propagules, such as those of $A$. marina, the requirement for no inundation to allow anchoring does not 
Fig. 4 Mean mangroves per cell along the $x$ coordinates of the tidal flat for the model without positive feedback and without elevationdependent seedling mortality (dotted line), with elevation-dependent seedling mortality and without positive feedback (continuous line with asterisks), and with both positive feedback and elevation-dependent seedling mortality (continuous line)

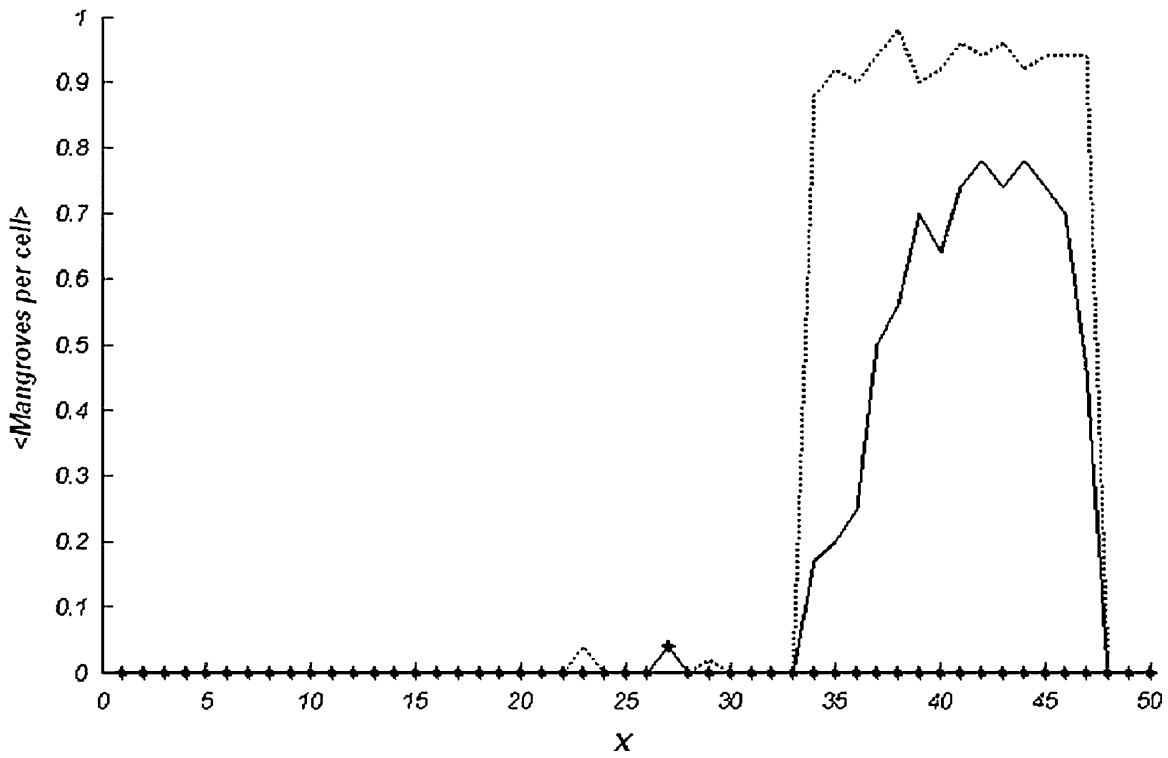

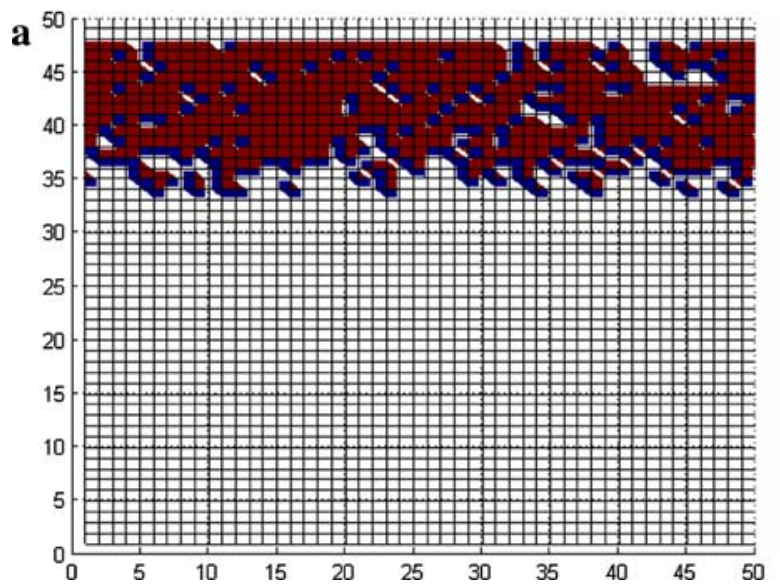

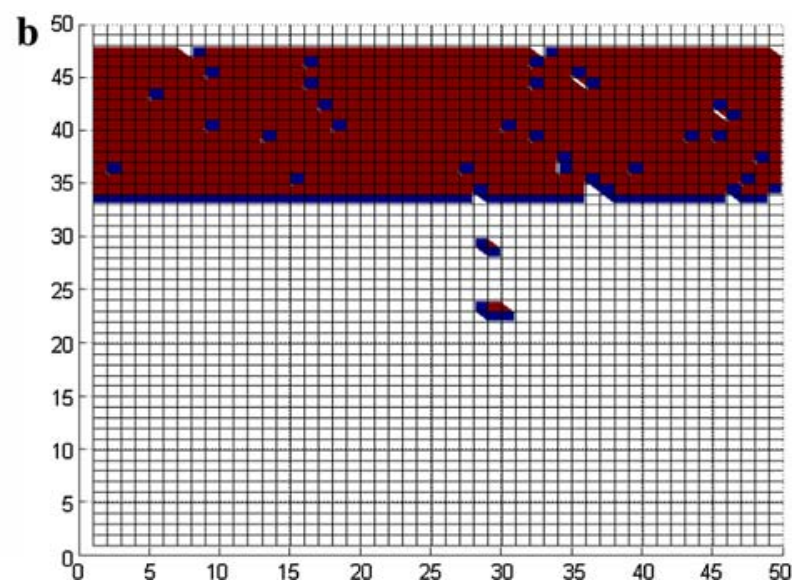

Fig. 5 The spatial distribution of adult mangrove trees with (a) and without (b) elevation-dependent seedling mortality. Elevation and seedling mortality vary over $y$-axis with highest mortality and lowest elevation in the origin

predict general mangrove range limits. The results do indicate, however, that in case of sea-level changes the range limits for A. marina can be expected to shift away, with encroachment land-inward (e.g. Saintilan and Williams 1999) (enabled by propagule transportation) and loss at the seaward limit due to prolonged inundation.

The inclusion of elevation and elevation-dependent seedling mortality showed that the seaward range limit and mangrove expansion may be limited not only by inundation and propagule establishment but by seedling mortality due to high wave energy. Recovery is indeed usually unsuccessful in areas with higher wave energy and seedling mortality (Riley and Kent 1999). The model results showed that the presence of positive feedback between mangrove trees and seedling survival may enable mangroves to exist in (and expand to) areas where unaided establishment is unsuccessful. Conversely, after deforestation and severe erosion previously inhabited areas could become unsuitable for natural recovery not only due to changes in for instance inundation times (Baldwin et al. 2001; Bosire et al. 2008; Blasco et al. 1996; Ferwerda et al. 2007), but through loss of the positive feedback that allowed establishment in the first place. This confirms the hypothesis that a 


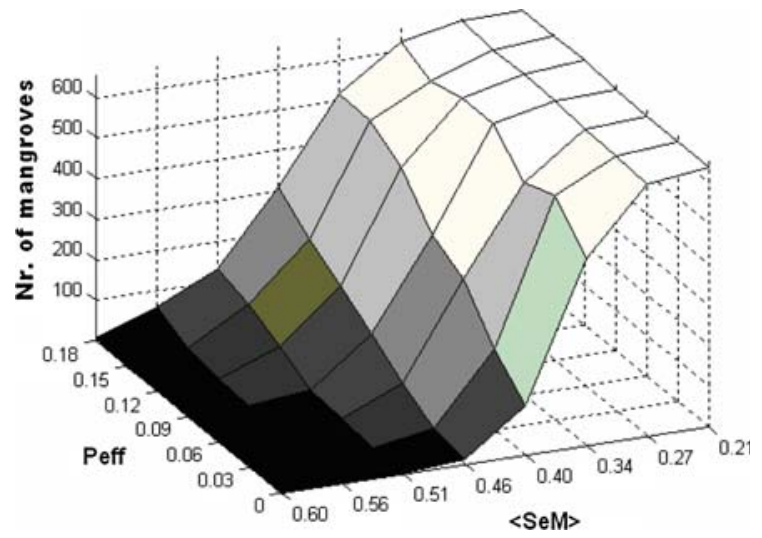

Fig. 6 Number of adult mangrove trees after 200 years starting with 10 trees at different levels of positive feedback $\left(P_{e f f}\right)$ and seedling mortality at the approximate centre of the mangrove range $(<$ SeM $>)$

positive feedback can strongly influence recovery (Van Langevelde and Prins 2007). Furthermore it suggests that, if possible, stands of trees should be left not only to act as propagule sources, but to serve as footholds or nursing ground for new seedlings. This prediction in turn agrees with recent findings on the positive effect of stands on regrowth of mangroves after hurricanes (Ferwerda et al. 2007). If no such stands are present, methods such as those used by Riley and Kent (1999) could be used to create them with particular care taken to provide the seedlings with the protection given by the adult mangroves.

We have made several simplifying assumptions regarding spatial structure of the tidal flat, wave stress effects and life-history. Furthermore we assumed that dispersal of floating propagules is a stochastic, almost random, process. In real-life systems, however, there will be creeks and channels, eddies and shallows, all influencing local conditions, seedling survival and dispersal. The results of our model are, however, not very sensitive to changes in dispersal, and increased variability in space should not change the fundamental importance of the positive feedback, although inclusion of spatial structure might allow selection of particular areas suitable for small initial populations and successful subsequent spread. The tidal regime modelled here is still relatively simple. If more complex dynamics are included questions regarding timing of propagule production versus tidal regimes could be investigated. The stage-specific mortalities assumed here will influence overall growth and can influence the relative importance of seedlings. It is generally accepted, however, that seedling establishment and survival are the most important aspects of successful mangrove recovery and growth (Bosire et al. 2008). Finally, including biotic interactions such as seed predation could alter the conclusions if seed predation is disproportionally high in areas with established mangroves.

The initial hypothesis, that positive feedbacks can determine the outcome of mangrove recovery, is confirmed for A. marina. The positive feedback we modelled is specific for A. marina, since it works through pneumatophores protecting seedlings from high wave energy, algae and plastics (Bhat et al. 2004; Shigeyasu 2000). Many other mangrove tree species do not have such pneumatophores extending from a canopy (Hogarth 1999) and hence do not have this specific feedback. The influence of positive feedbacks in mangroves, however, is not dependent on the specific mechanism involved. Given that positive feedbacks have been found to be present in various systems (Scheffer et al. 2001) such as, for example, savannas (De Knegt et al. 2008; Van Langevelde et al. 2003), seagrasses (De Boer 2007; Van Langevelde and Prins 2007), and tidal flats (Van de Koppel et al. 2001), it may not be unlikely that some form of positive feedback occurs in other types of mangroves. In this context especially soil feedbacks involving nutrient concentration and sediment collection (De Boer 2007) are of interest, considering their importance for mangrove recruitment (Clarke and Kerrigan 2002). Studying feedback mechanisms in mangroves could follow studies in other systems. Positive feedbacks often work through facilitative interactions, for example, increasing infiltration of rainfall in the soil by plants in water-limited systems (Rietkerk et al. 2002), or promoting disturbances such as fire by grass as fuel load to reduce competition with trees in savannas (Van Langevelde et al. 2003). These positive feedback mechanisms can be detected by investigating organisms under stressful conditions.

Since it is generally true that the higher the stress, the more important the role of positive feedback in determining ecosystem stability and recovery becomes (Scheffer et al. 2001, Van Langevelde and Prins 2007), positive feedbacks, if present, are likely to be even more crucial in recovery situations than in 'normal' ecosystems. We argue that restoration efforts could benefit from further investigating and 
understanding the possible presence and mechanisms of positive feedbacks in mangrove systems.

Open Access This article is distributed under the terms of the Creative Commons Attribution Noncommercial License which permits any noncommercial use, distribution, and reproduction in any medium, provided the original author(s) and source are credited.

\section{References}

Alongi D (2002) Present state and future of the world's mangrove forests. Environ Conserv 29:331-349. doi:10.1017/ S0376892902000231

Baldwin A, Egnotovich M, Ford M, Platt W (2001) Regeneration in fringe mangrove forests damaged by Hurricane Andrew. Plant Ecol 157:149-162. doi:10.1023/A:101394 1304875

Barbier E (2006) Natural barriers to natural disasters: replanting mangroves after the tsunami. Front Ecol Environ 4:124131. doi:10.1890/1540-9295(2006)004[0124:NBTNDR] 2.0.CO;2

Bhat NR, Suleiman MK, Shahid SA (2004) Mangrove, Avicennia marina, establishment and growth under the arid climate of Kuwait. Arid Land Res Manage 18:127-139. doi:10.1080/15324980490280799

Blasco F, Saenger P, Janodet E (1996) Mangroves as indicators of coastal change. Catena 27:167-178. doi:10.1016/03418162(96)00013-6

Bosire JO, Dahdouh-Guebas F, Walton M, Crona BI, Lewis RRIII, Field C, Kairo JG, Koedam N (2008) Functionality of restored mangroves: a review. Aquat Bot 89:251-259. doi:10.1016/j.aquabot.2008.03.010

Bunt JS (1996) Mangrove zonation: an examination of data from seventeen riverine estuaries in tropical Australia. Ann Bot UK 78:333-341. doi:10.1006/anbo.1996.0128

Clarke PJ (1993) Dispersal of grey mangrove (Avicennia marina) propagules in south-eastern Australia. Aquat Bot 45:195-204. doi:10.1016/0304-3770(93)90021-N

Clarke PJ (1995) The population dynamics of the mangrove Avicennia marina: demographic synthesis and predictive modelling. Hydrobiol 295:83-88. doi:10.1007/BF0002 9114

Clarke PJ, Allaway WG (1993) The regeneration niche of the grey mangrove (Avicennia marina)-effects of salinity light and sediment factors on early growth and survival in the field. Oecologia 93:548-556. doi:10.1007/BF00328964

Clarke PJ, Kerrigan RA (2002) The effects of seed predators on the recruitment of mangroves. J Ecol 90:728-736. doi: 10.1046/j.1365-2745.2002.00705.x

Clarke PJ, Myerscough PJ (1991) Buoyancy of Avicennia marina propagules in south-eastern Australia. Aust J Bot 39:77-83. doi:10.1071/BT9910077

Clarke PJ, Kerrigan RA, Westphal CJ (2001) Dispersal potential and early growth in 14 tropical mangroves: do early life history traits correlate with patterns of adult distribution. J Ecol 89:648-659. doi:10.1046/j.0022-0477. 2001.00584.x
De Boer WF (2002) The rise and fall of the mangrove forests in Maputo Bay, Mozambique. Wetlands Ecol Manage 10: 313-322. doi:10.1023/A:1020389420591

De Boer WF (2007) Seagrass-sediment interactions, positive feedbacks and critical thresholds for occurrence, a review. Hydrobiol 591:5-24. doi:10.1007/s10750-007-0780-9

De Boer WF, Rydberg L, Saide V (2000) Tides, tidal currents and their effects on the intertidal ecosystem of the southern bay, Inhaca Island, Mozambique. Hydrobiol 428: 187-196. doi:10.1023/A:1004030605474

De Knegt HJ, Groen AT, Van de Vijver CADM, Prins HHT, Van Langevelde F (2008) Herbivores as architects of savannas: inducing and modifying spatial vegetation patterning. Oikos 117:543-554. doi:10.1111/j.0030-1299. 2008.16403.x

Delgado P, Hensel PF, Jiménez JA, Day JW (2001) The importance of propagule establishment and physical factors in mangrove distributional patterns in a Costa Rican estuary. Aquat Bot 71:157-178. doi:10.1016/S0304-3770 (01)00188-7

ElAmry M (1998) Population structure, demography and life tables of Avicennia marina (Forssk.) Vierh. at sites on the eastern and western coasts of the United Arab Emirates. Mar Freshw Res 49:303-308. doi:10.1071/MF97144

Ellison AM (2000) Mangrove restoration: do we know enough? Restor Ecol 8:219-229. doi:10.1046/j.1526-100x.2000. 80033.x

Ellison AM, Mukherjee BB, Karim A (2000) Testing patterns of zonation in mangroves: scale dependence and environmental correlates in the Sundarbans of Bangladesh. Ecology 88:813-824. doi:10.1046/j.1365-2745.2000.00500.x

Ferwerda JG, Ketner P, McGuinness KA (2007) Differences in regeneration between hurricane damaged and clear-cut mangrove stands 25 years after clearing. Hydrobiol 591: 35-45. doi:10.1007/s10750-007-0782-7

Hogarth PJ (1999) The biology of mangroves. Oxford University Press Inc., New York

Imbert D, Rousteau A, Scherrer P (2000) Ecology of mangrove growth and recovery in the Lesser Antilles: state of knowledge and basis for restoration projects. Restor Ecol 8:230-236. doi:10.1046/j.1526-100x.2000.80034.x

Kitaya Y, Jintana V, Piriyayotha S, Jaijing D, Yabuki K, Izutani S, Nishimiya A, Iwasaki M (2002) Early growth of seven mangrove species planted at different elevations in a Thai estuary. Trees (Berl) 16:150-154. doi:10.1007/ s00468-002-0165-7

Minchinton TE, Dalby-Ball M (2001) Frugivory by insects on mangrove propagules: effects on the early life history of Avicennia marina. Oecologia 129:243-252. doi:10.1007/ s004420100715

Nagelkerken I, Blaber SJM, Bouillon S, Green P, Haywood M, Kirton LG, Meynecke J-O, Pawlik J, Penrose HM, Sasekumar A, Somerfield PJ (2008) The habitat function of mangroves for terrestrial and marine fauna: a review. Aquat Bot 89:155-185. doi:10.1016/j.aquabot.2007.12.007

Rietkerk M, Boerlijst MC, Van Langevelde F, HilleRisLambers R, Van de Koppel J, Kumar L, Prins HHT, De Roos AM (2002) Self-organization of vegetation in arid ecosystems. Am Nat 160:524-530. doi:10.1086/342078

Riley RW, Kent CPS (1999) Riley encased methodology: principles and processes of mangrove habitat creation and 
restoration. Mangroves Salt Marshes 3:207-213. doi:10. 1023/A:1009963124225

Saenger P, Snedaker SC (1993) Pantropical trends in mangrove above-ground biomass and annual litterfall. Oecologia 96:293-299. doi:10.1007/BF00317496

Saintilan N, Williams RJ (1999) Mangrove transgression into saltmarsh environments in south-east Australia. Glob Ecol Biogeogr 8:117-124. doi:10.1046/j.1365-2699.1999. 00133.x

Scheffer M, Carpenter S, Foley J, Folke C, Walker B (2001) Catastrophic shifts in ecosystems. Nature 413:591-596. doi: $10.1038 / 35098000$

Shigeyasu T (2000) Study of gray mangrove (Avicennia marina) afforestation for greening a desert coast: ecology of gray mangrove seeds in the Persian Gulf. Jpn. J. Ecol. 50:121-131

Twilley RR, Rivera-Monroy VH, Chen R, Botero L (1998) Adapting an ecological mangrove model to simulate trajectories in restoration ecology. Mar Pollut Bull 37:404-419. doi:10.1016/S0025-326X(99)00137-X

Van de Koppel J, Herman PMJ, Thoolen P, Heip CHR (2001) Do alternate stable states occur in natural ecosystems? Evidence from a tidal flat. Ecology 82:3449-3461

Van Langevelde F, Prins HHT (2007) Resilience and restoration of soft-bottom near-shore ecosystems. Hydrobiol 591:1-4. doi:10.1007/s10750-007-0779-2

Van Langevelde F, Van de Vijver CADM, Kumar L, Van de Koppel J, De Ridder N, Van Andel J, Skidmore AK, Hearne J, Stroosnijder L, Bond WJ, Prins HHT, Rietkerk M (2003) Effects of fire and herbivory on the stability of savanna ecosystems. Ecology 84:337-350. doi:10.1890/0012-9658 (2003)084[0337:EOFAHO]2.0.CO;2

Walters BB (2004) Local management of mangrove forests in the Philippines: successful conservation of efficient resource exploitation? Hum Ecol 32:177-195. doi:10.1023/B:HUEC. 0000019762.36361 .48 